\title{
INFANTILE PYLORIC STENOSIS
}

\author{
BY \\ J. W. GERRARD, J. A. H. WATERHOUSE and D. G. MAURICE \\ From the Departments of Paediatrics and Child Health and Medical Statistics, \\ University of Birmingham
}

(RECEIVED FOR PUBLICATION JULY 4, 1955)

It would seem, from the studies of Carter and Powell (1954) and of McKeown, MacMahon and Record (1952), that both genetic and environmental factors play a part in the aetiology and development of infantile pyloric stenosis. The latter group of workers have stressed the importance of postnatal environmental influences. Their studies, based on data derived from more than 1,000 cases treated in the Children's Hospital, Birmingham, between 1940 and 1951, showed that symptoms, on average, developed later in babies born in hospital than in those delivered at home, and in first-born than in those born subsequently. In an earlier survey, based on 578 cases operated on between 1945 and 1950, they (McKeown et al., 1951c) had also found that the size of the tumour was roughly proportional to the age of the baby at operation. These observations, coupled with the rarity with which the tumour is found at birth, strongly suggested not only that the growth of the tumour was a post-natal phenomenon, but also that its rate of growth was conditioned by post-natal factors.

The purpose of the present study was first to confirm, by direct measurement of the tumour at operation, that its size was indeed proportional to the age of the baby; secondly to enquire into possible post-natal influences determining its rate of development; and thirdly to attempt to evaluate the role of genetic factors.

\section{Material and Methods}

The pyloric tumour was measured at operation, using calipers and a metal ruler, in 51 cases selected at random during 1951 and 1952. The external dimensions (length and diameter of the tumour) were measured in all cases. The internal dimensions (the thickness of the muscle coat and the length of the incision) were measured in 43 ; the latter measurements were less easy to record accurately and variations in the thickness of the pyloric muscle were smaller, partly owing to retraction of the muscle after section and partly because the radius and not the diameter was being measured. These cases were analysed for factors influencing tumour size. A further 101 cases, treated between 1949 and 1953, were taken at random from the hospital files and together with the first series were subjected to careful examination for possible post-natal environment factors affecting the rate of development of symptoms.

\section{Results}

Size of Tumour at Operation.-The data are represented diagrammatically in Fig. 1. The size

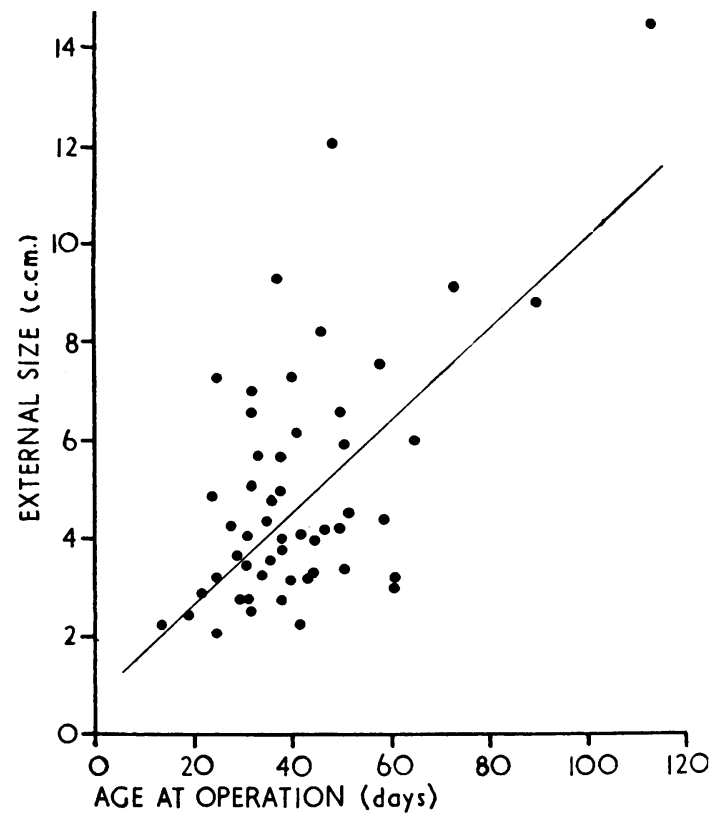

FIG. 1.-Scatter diagram and regression line relating external size of tumour to age at operation.

of the pyloric tumour (external measurements) was found to be closely correlated with the age of the infant at operation, confirming McKeown's observations. Tumour size was also correlated with duration of symptoms, but not with weight. Thus, 
duration of symptoms, tumour size and age at operation were all correlated. Within certain assumptions the method of partial correlation can be used to remove the effects of a common factor and to discover the remaining relationship between two variables. When this was applied it was found that the correlation between external dimensions and age at operation remained significant when the effect of duration of symptoms was removed, but not vice versa. There was no close correlation between the internal dimensions of the tumour and the age at operation, probably because the measurements themselves were less accurate, for reasons already stated, and because differences between large and small tumours were less conspicuous on internal size.

Environmental Factors: Frequency of Feeds. When analysing the 51 cases whose tumours were measured at operation, it was noted that the four premature infants in this group developed their symptomsusually vomiting - almost as quickly as the fullterm babies in the series. The four premature babies were born, on average, five weeks before the expected date of delivery, but they developed their symptoms only five to $\mathbf{1 0}$ days later than their fullterm counterparts. It was concluded, therefore, that the environmental factor influencing the rate of development of symptoms was brought into play at a comparatively early age even in the premature babies; it was suspected that this factor might be related to feeds. The introduction of food into the stomach, especially if rich in fat, like milk, is known to stimulate pyloric contraction. It seemed quite possible that more frequent feeding schedules might be associated with the earlier onset of symptoms, and less frequent feeding schedules with a later onset of symptoms.

All cases under analysis were, therefore, divided into two groups, those fed three-hourly and those fed four-hourly (Table 1). It is seen that the babies fed three-hourly developed their symptoms significantly earlier than those fed four-hourly. The

TABLE 1

AGE AT ONSET OF VOMITING IN RELATION TO FEEDING SCHEDULE AND PLACE OF BIRTH

\begin{tabular}{|c|c|c|c|c|}
\hline \multirow{2}{*}{\multicolumn{2}{|c|}{$\begin{array}{l}\text { Feeding } \\
\text { Schedule }\end{array}$}} & \multicolumn{2}{|c|}{ Place of Birth } & \multirow{2}{*}{$\begin{array}{l}\text { Hospital } \\
\text { and Home }\end{array}$} \\
\hline & & Hospital & Home & \\
\hline $\begin{array}{ll}\text { 3-hourly } & \ldots \\
\text { 4-hourly } & \ldots\end{array}$ & $\begin{array}{l}. \\
.\end{array}$ & $\begin{array}{c}21 \cdot 7 \text { days } \\
(30)^{*} \\
27 \cdot 3 \text { days } \\
(66)\end{array}$ & $\begin{array}{c}21 \cdot 5 \text { days } \\
\text { (25) } \\
26 \cdot 6 \text { days } \\
\text { (31) }\end{array}$ & $\begin{array}{l}21 \cdot 6 \text { days } \\
\text { (55) } \\
27 \cdot 1 \text { days } \\
\quad(97)\end{array}$ \\
\hline 3- and 4-hourly & . & $\begin{array}{c}25 \cdot 6 \text { days } \\
(96)\end{array}$ & $\begin{array}{c}24 \cdot 3 \text { days } \\
(56)\end{array}$ & \\
\hline
\end{tabular}

* Figures in parentheses refer to numbers of cases. mean age when vomiting first started in those fed three-hourly was 21.6 days (after approximately 129 feeds) and $27 \cdot 1$ days (after approximately 135 feeds) in those fed four-hourly. The mean birth weight, as might be expected, was rather less in those fed three-hourly (average $7 \cdot 1 \mathrm{lb}$.) than in those fed four-hourly (average $7 \cdot 7 \mathrm{lb}$.); nevertheless, the correlation between birth weight and the age when symptoms first developed was negligible. It should be noted that the mean age when vomiting first started was not, apparently, influenced by the place of birth. Those fed three-hourly, whether born at home or in hospital, started to vomit on average on the 22nd day, and those fed four-hourly started to vomit on the 27 th or 28 th day. The differences between the rate of development of symptoms in those born at home and in hospital and fed three-hourly ( $0 \cdot 2$ day) and fed four-hourly $(0.7$ day) are insignificant, though in both instances it is the baby born in hospital who begins to vomit later.

A comparison of the feeding schedules of babies born at home and in hospital reveals (Table 1) that of those born in hospital (in Birmingham) approximately only one-third are fed three-hourly, whereas of those born at home nearly one half are fed threehourly during the first few critical weeks. This, no doubt, explains the earlier onset of symptoms in those born at home. Further analysis has shown that birth rank also influences the rate of development of symptoms (Table 2), second and third

TABLE 2

MEAN AGE AT VOMITING IN DAYS

\begin{tabular}{c|l|l|l}
\hline $\begin{array}{c}\text { Birth } \\
\text { Rank }\end{array}$ & 3-Hourly & 4-Hourly & Total \\
\hline 1 & $24 \cdot 5(17)^{*}$ & $30 \cdot 8(37)$ & $28 \cdot 9(54)$ \\
2 & $21 \cdot 1(17)$ & $24 \cdot 9(30)$ & $23 \cdot 5(47)$ \\
3 & $17 \cdot 9(10)$ & $24 \cdot 2(18)$ & $22 \cdot 0(28)$ \\
$4+$ & $21 \cdot 1(11)$ & $25 \cdot 4(12)$ & $23 \cdot 4(23)$ \\
\hline
\end{tabular}

* Figures in parentheses refer to numbers of cases.

births tending on average to develop their symptoms increasingly early. The acceleration of the onset of symptoms, which is not apparent in fourth and subsequent births, is greatest in those fed threehourly, and is not influenced by the place of birth.

Genetic Factors. There are two factors which are difficult to reconcile with the suggestion that pyloric stenosis is genetically determined; first that there appears to be an excess of first-borns (McKeown et al., 1951a), and secondly that there is no greater incidence of the disease in first cousins than in the general population (McKeown et al., 1951b). With 
regard to the second observation we have no additional data to offer; with regard to the first we have. We compared the distribution of our cases by place of birth-home or hospital-with that for Birmingham as a whole during the same period, viz., 1949-1953 (Padley, 1954). The agreement was found to be close, and the sample, therefore, a fair and unbiased one. We found, however, no increase of first births over expectation (Table 3). In fact the

TABLE 3

INCIDENCE OF PYLORIC STENOSIS BY BIRTH RANK COMPARED WITH THE EXPECTED INCIDENCE*

\begin{tabular}{c|cc|cc}
\hline \multirow{3}{*}{ Birth Rank } & \multicolumn{2}{|c|}{ Both Sexes } & \multicolumn{2}{|c}{ Males } \\
\cline { 2 - 3 } & Observed & Expected & Observed & Expected \\
\hline 1 & 54 & $57 \cdot 9$ & 50 & $48 \cdot 8$ \\
2 & 47 & $43 \cdot 8$ & 37 & 36.9 \\
3 & 28 & 23.7 & 22 & 20.0 \\
4 & 13 & 11.9 & 12 & $10 \cdot 0$ \\
5 & 4 & $6 \cdot 2$ & 2 & $5 \cdot 2$ \\
$6+$ & 6 & 8.6 & 5 & $7 \cdot 1$ \\
\hline Total & 152 & $152 \cdot 1$ & 128 & $128 \cdot 0$ \\
\hline
\end{tabular}

* From City of Birmingham Annual Abstract of Statistics, Vol. 2.

distribution by birth rank is remarkably close to expectation, particularly in males.

\section{Discussion}

We have been able to confirm the findings of McKeown et al. (1951c) that the size of the pyloric tumour is proportional to the age of the baby at the time of operation.

We have also shown that the earlier onset of symptoms in babies born at home, and its later onset in those born in hospital, and also in first births, would seem to be due simply to difference in feeding schedules. Most babies delivered in hospital-and this includes a high proportion of first births-are fed four-hourly; such babies tend to develop symptoms late. A higher proportion of babies born at home are fed three-hourly, and such babies tend to develop symptoms early. It would seem that the more frequently a baby is fed, other things being equal, the sooner will symptoms develop. The baby's early environment, whether in the home or in hospital, apart from its influence on the frequency with which feeds are offered, appears to have no demonstrable effect on the rate at which symptoms develop. Since feeding is the necessary stimulus for the development of the tumour it is not surprising that it has been observed only exceptionally at birth or soon after, for babies probably do not imbibe much fluid in utero.

Whether the quality of the feed offered, human or cow's, half-cream or full-cream milk, is also of aetiological import we are unable, as yet, to say.
The feeding régimes of the babies in our series were very variable; many began life on human milk and later were offered, either because the maternal supply was subsiding, or because the baby was beginning to vomit, feeds derived ultimately from the cow. As has already been mentioned, premature babies, although fed three-hourly, do not always develop their symptoms as rapidly as might be expected. This may be because there is often a delay of two or three days before feeds are first introduced in prematures, but it may also be because premature babies are usually given dilute feeds, which are low in fat. It is unlikely to be due to the fact that these babies are kept in hospital longer than full-term babies, for, as we have shown, the place of birth in itself is unimportant.

Variations with which feeds are offered may explain the discrepancies to which McKeown has drawn attention between babies born at home and those delivered in hospital, but they cannot explain why a tumour develops in the first place, for all babies are fed, and only three per 1,000 develop a tumour.

The findings of MacMahon and McKeown (1955) in their study of pyloric stenosis in twins, that there is no increased incidence in monozygous twins, makes it very difficult to postulate that genetic factors have any direct bearing on the aetiology of this disorder. A further study by these authors (McKeown and MacMahon, 1955) on the incidence of pyloric stenosis in parent and child draws attention to the interesting fact that it is as common in the mother as it is in the father of an affected child. In the parents the ratio of male to female is $1: 1$; in the children it is, as expected, $4: 1$. The same relationship is present in the group of cases studied by Carter and Powell (1954), but they did not comment on it. The unexpectedly high frequency of the disorder in the mother suggests that she has a greater influence in the production of the disease in her child than the father. This influence may be in part perinatal, or milk-borne, or perhaps even psychological. Though psychological factors may be pertinent, they are difficult to evaluate and should take second place, in our view, to a more detailed investigation of feeding and ingredients of the milk. A clue to the aetiology of the disorder may be given by the knowledge that whatever stimulates pyloric hypertrophy and contraction is inhibited by atropine methyl nitrate.

\section{Summary}

The size of the pyloric tumour is proportional to the age of the baby at operation.

The rapidity with which symptoms develop is related to the frequency with which the baby is fed; 
babies fed three-hourly develop symptoms on average in 21.6 days, babies fed four-hourly develop symptoms on average in $27 \cdot 1$ days.

We have not found any increased incidence of the disease in first-borns.

We are grateful to Dr. Padley of the Central Statistical Office of the City of Birmingham, for generously giving us access to his material, to the staff of the Children's Hospital, Birmingham, for allowing us to study their patients, and to Professor McKeown and Dr. MacMahon for reading a draft of this paper and for allowing us to see the typescripts of two of their papers.

\section{RFFERENCES}

Carter, C. O. and Powell, B. W. (1954). Lancet, 1, 746.

Mckeown T. and MacMahon, B. (1955). Archives of Disease in Childhood, 30, 497.

Childhood, 30, 497. and Record, R. G. (1951a). Ann. Eugen., Camb., 16, 249.

- - (1951b). Ibid., 16, 260.

- - (1952). Archives of Disease in Childhood, 27, 386. Padley, R. (1954). Personal communication. 